\title{
ESTUDIO DE LA NUEVA PORNOGRAFÍA Y RELACIÓN SEXUAL EN JÓVENES
}

\section{NEW PORNOGRAPHY AND THE MODIFICATION OF SEXUAL RELATIONS AMONG YOUTH}

\author{
Lluis Ballester Brage \\ Universitat de les IIles Balears \\ Iluis.ballester@uib.es \\ Carmen Orte Socías \\ Universitat de les Illes Balears \\ carmen.orte@uib.es \\ Rosario Pozo Gordaliza \\ Universitat de les Illes Balears \\ rosario.pozo@uib.es
}

Resumen: No se puede negar el impacto que tiene sobre las conductas sexuales, así como sobre las relaciones de género, la "nueva pornografía" distribuida por internet. Para intentar conocer este problema hemos realizado un estudio con un enfoque, teórico y empírico bien fundamentado. En cuanto a la metodología, el estudio fue diseñado para obtener una muestra de actividades en la esfera privada, en relación al consumo de pornografía en internet, diferenciadas por género. Entre los resultados y conclusiones podemos destacar: 1) la pornografía en internet puede influir sobre las actitudes sexuales, valores morales y actividad sexual de los juventud; 2) los varones son los grandes consumidores de pornografía en internet y los que presionan más en el cambio de las prácticas sexuales, y 3) el fácil acceso a la pornografía en internet forma parte de un entorno altamente sexualizado.

Palabras clave: Nueva pornografía, ritualización, habitus, esquemas de percepción, prácticas sexuales, prostitución.

\begin{abstract}
The impact of internet-distributed "new pornography" on sexual behaviour and gender relations cannot be denied. To solve this problem, we have conducted a study based on a well-founded theoretical and empirical approach. The study was designed to obtain a sample of activities in the private sphere, in relation to the consumption of pornography on the internet, differentiated by gender. Results and conclusions: 1) pornography on the internet can influence sexual attitudes, moral values, and sexual activity of youth; 2) males are the greatest consumers of pornography on the internet and are the most likely to experience changes in sexual practices; and 3) easy access to pornography on the internet is part of a highly sexualized environment.
\end{abstract}

Key words: New pornography, ritualization, "habitus", social perception, sexuality, prostitution. 


\section{Nueva pornografía ${ }^{1}$}

No se puede negar el impacto que tiene sobre las conductas sexuales, así como sobre las relaciones de género, la "nueva pornografía" distribuida por internet. La familiaridad con prácticas de riesgo, la descontextualización de la sexualidad, la inmediatez, la simplificación de las relaciones interpersonales, así como la vinculación con nuevas modalidades de prostitución, convierten a la nueva pornografía en un fenómeno de especial relevancia para la comprensión de las relaciones interpersonales (Döring, 2009; Weitzer, 2010).

La pornografía ha sido objeto de debate desde su aparición, hace al menos dos mil años en la Roma imperial. Desde posiciones que la defienden como una modalidad de la libertad de expresión, hasta quienes la critican por su vinculación a la explotación del cuerpo de las mujeres ${ }^{2}$. Sin embargo, se ha modificado sustancialmente. No se puede comparar la pornografía convencional con la nueva pornografía. La pornografía convencional se basa en imágenes impresas o filmaciones, distribuidas por canales ilegales o por las distribuidoras de revistas, con venta en sex-shop o en comercios de diversos productos (prensa, vídeo, en especial). La dificultad de acceso, así como el coste de las imágenes, la exposición de quien la adquiere, así como otros factores, limitaban su impacto.

La nueva pornografía, distribuida por internet, modifica la distribución superando las limitaciones observadas, pero también modifica los sistemas de producción y las consecuencias que de ella se derivan (Kor, 2014: 862). Se puede hablar de "nueva pornografía" a partir de cinco notas características:

1. Se basa en filmaciones con mejoras constantes en los niveles de calidad, abandonando la distribución de imágenes en soportes tradicionales (jpg).

- La oferta es mayoritariamente gratuita, aunque se vincule a empresas capitalistas de dimensiones variables y se relacione directamente con cuatro mercados, en expansión en el mundo de internet:

- el de la publicidad

- el de las filmaciones pornográficas de alta calidad (en directo, por encargo, seleccionadas por catálogo, etc.)

- el de los contactos libres

- el de los contactos pagados (prostitución)

2. Las dimensiones de la oferta son aparentemente ilimitadas, con producción y distribución constante en casi todo el mundo de centenares de miles de filmaciones, constantemente ampliadas ${ }^{3}$.

1 No creemos necesario volver a definir la pornografía, nos basamos en los autores que han establecido la nueva conceptualización sobre la misma: Ayres y Haddock (2009), Flood (2007) y Poza y Ares (2011), entre otros.

2 Como sabemos, hasta recientemente casi no existía pornografía masculina. La capacidad de compra de grandes sectores de mujeres, así como el aumento de los canales de demanda y distribución de imágenes y vídeos han hecho aparecer un tímido mercado de pornografía para mujeres. El mercado de pornografía gay existe y es pujante en Occidente desde los años sesenta del siglo pasado.

3 No se sustituyen las filmaciones, sólo se acumulan cada vez más. Se pueden encontrar filmaciones de hace cuarenta años en unos u otros servidores de internet. 
3. Tampoco tienen límite las prácticas sexuales que se pueden observar, desde las más convencionales hasta prácticas de gran riesgo o directamente ilegales.

4. Se pueden encontrar diversos niveles de interactividad, desde la mínima interacción (visualización de filmaciones), hasta la relación cara a cara a partir del contacto a distancia, en un nuevo contexto de acceso a la prostitución, pasando por modalidades de diversa implicación.

La nueva pornografía tiene un impacto desconocido hasta el gran desarrollo de internet, en los últimos diez años. Su presencia se ha normalizado para la mayoría de la población occidental, en especial para la población masculina, aumentando la oferta y la demanda (D'Orlando, 2011). Su consumo no ha dejado de aumentar, generando adicción en los consumidores habituales ${ }^{4}$ (Young, 2008). Por ese motivo, no puede ignorarse su impacto sobre dichos consumidores y las relaciones que establecen. Se han formulado cuatro hipótesis basadas en la literatura científica, entendidas como respuestas tentativas a las preguntas sobre el impacto de la nueva pornografía. Nuestras hipótesis de investigación se centran en cuatro impactos relacionados:

Hipótesis 1. De acuerdo con la literatura científica, se espera mayor prevalencia del consumo de nueva pornografía entre los hombres ${ }^{5}$. También se espera mayor consumo de nueva pornografía entre los grupos de edad que usan con mayor frecuencia y durante más tiempo de los servicios de internet, en especial entre los jóvenes.

Hipótesis 2. El impacto de la nueva pornografía es superior en los hombres, modificando sus esquemas perceptivos y, a medio plazo, los habitus de los grupos de grandes consumidores.

Hipótesis 3. La nueva pornografía modifica las prácticas sexuales de los grandes consumidores, en dos direcciones complementarias, la familiaridad con prácticas de riesgo y la demanda a sus parejas sexuales de dichas prácticas o el consumo de prostitución para realizarlas.

Hipótesis 4. La nueva pornografía y las opciones que ofrece internet, generan un efecto complementario de los considerados en la tercera hipótesis, una ritualización de las relaciones sexuales ${ }^{6}$. La ritualización de las relaciones se basa en la simplificación de las relaciones, desde formas rituales rígidas (con pautas estrictas de elevada expectativa y bajo riesgo personal), hasta formas rituales flexibles (con unas reglas de juego que permiten una amplia variedad de desarrollos). Un ejemplo de la ritualización se observa en la transformación del acceso a la relación sexual, mediante el uso de mediadores de contacto explícito en internet.

Uno de los efectos que estudiamos, vinculado a la nueva pornografía, es la creciente ritualización de las relaciones, es decir, el desarrollo de una parte de los nuevos rituales de relación se explica por la importante presencia de la nueva pornografía. Dicha presencia es especialmente relevante entre los hombres, a todas las edades, modificando las relaciones, las expectativas, los criterios para evaluarlas, las modalidades de las prácticas sexuales deseadas y otros aspectos de las relaciones inter-

4 Puede consultarse la revista especializada Sexual Addiction \& Compulsivity. Para una revisión de los estudios sobre conducta compulsiva e internet, puede consultarse Reay, Attwood y Goo$\operatorname{der}(2013)$.

5 Los estudios sobre el impacto de la pornografía sobre la conducta femenina muestran que su importancia es relevante, pero siempre inferior a la de los hombres (Rogala y Tydén, 2003).

6 Ritualización a través de determinadas prácticas habituales, basadas en un determinado universo simbólico que se ha conformado como habitus específico. 
personales. Un efecto de la propia ritualización es la legitimación de determinadas prácticas relativas a la sexualidad ${ }^{7}$ (Osborne y Guasch, 2003).

\section{Método}

Diseño. Se trabaja con un diseño de historias de vida con jóvenes (16-29 años) en Mallorca (Islas Baleares - España). Dicho diseño cualitativo no se ha preparado para contrastar las hipótesis, sino para explorar su consistencia previamente al desarrollo de un estudio basado en encuesta. Se puede considerar como una primera etapa exploratoria. La segunda etapa, antes del estudio de encuesta, consiste en una consulta de informantes cualificados. Todas las entrevistas fueron realizadas bajo la dirección del equipo de investigación.

Muestra. La muestra se selecciona entre jóvenes de Mallorca (Islas Baleares - España), de acuerdo con los criterios establecidos a continuación. Se estimó que la muestra no probabilística estructural, debería considerar tres criterios que definen las cuotas básicas: edad (16-22 y 23-29), sexo y permanencia o no en el sistema educativo. El tamaño de referencia se estimó en 40 historias de vida, dado que la combinación de los tres criterios establecen ocho grupos ( 2 grupos de edad $\times 2$ sexos $x 2$ situaciones de actividad), de cada uno de los cuales se esperaba disponer de un máximo de 5 sujetos y un mínimo de 3. La realización efectiva de las historias se limitaba a la posibilidad de selección y a la capacidad de los colaboradores de investigación. Finalmente, se pudieron realizar 37 historias completas a lo largo de diciembre de 2012 y febrero de 2013.

Instrumentos. Se trabajó con el modelo de historia de vida desarrollado. Se recogieron en sobres cerrados y anónimos que incluían también una hoja elaborada por el propio joven (con una narración privada sobre sus prácticas sexuales).

Análisis de datos. Se utilizaron SPSS-21 para el tratamiento cuantitativo y NVIVO-10 para el tratamiento cualitativo de las transcripciones de las entrevistas y los textos aportados.

\section{Resultados}

Un diseño cualitativo exploratorio no se plantea la contrastación de hipótesis, sino sólo la consistencia de las mismas, su depuración y mejora para pasar a fases posteriores de la investigación. Por ese motivo, sólo se presentan resultados estadísticos de una parte de los análisis, presentando de forma discursiva el resto de respuestas y análisis realizados.

En primer lugar, se deben revisar las características de la muestra estructural. Tal como se ha dicho antes, se trata de 37 jóvenes, entrevistados en profundidad. Como se puede observar en la tabla 1, se ha conseguido mantener el equilibrio por edad, con un moderado desequilibrio por sexo. Las cuotas se han podido completar, con una reducción superior en las cuotas de mujeres.

7 Como se puede ver, nos situamos en el ámbito de la sociología de la sexualidad, de acuerdo a la definición de Osborne y Guasch (2003: 5): "se ocupa de definir qué es el sexo y qué no lo es, describe qué espacios y qué tiempos tiene adjudicados, qué actores lo ejecutan y cuáles no, de qué modo lo hacen y las razones y consecuencias sociales de todo ello". 


\begin{tabular}{|c|c|c|c|c|c|}
\hline & & & \multicolumn{2}{|c|}{ Sexo } & \multirow[b]{2}{*}{ Total } \\
\hline & & & Hombre & Mujer & \\
\hline \multirow{4}{*}{ Edad } & \multirow{2}{*}{$16-22$} & Frecuencia & 10 & 8 & 18 \\
\hline & & $\%$ & $47,6 \%$ & $50,0 \%$ & $48,6 \%$ \\
\hline & \multirow{2}{*}{$23-29$} & Frecuencia & 11 & 8 & 19 \\
\hline & & $\%$ & $52,4 \%$ & $50,0 \%$ & $51,4 \%$ \\
\hline \multirow{3}{*}{\multicolumn{2}{|c|}{ Total }} & Frecuencia & 21 & 16 & 37 \\
\hline & & $\%$ & $100,0 \%$ & $100,0 \%$ & $100,0 \%$ \\
\hline & & $\%$ & $56,8 \%$ & $43,2 \%$ & $100,0 \%$ \\
\hline
\end{tabular}

Tabla 1. Edad y sexo. Fuente: Elaboración propia.

Las cuotas relativas a la actividad también se pudieron respetar, tal como se observa en la tabla 2, ya que se esperaba una mayor presencia de jóvenes dedicados preferentemente a los estudios (60\%). La distribución por edad, con una importante presencia de menores de 23 años, incrementa justificadamente la representación de los estudios.

\begin{tabular}{|c|c|c|c|c|c|}
\hline & & & \multicolumn{2}{|c|}{ Sexo } & \multirow[b]{2}{*}{ Total } \\
\hline & & & Hombre & Mujer & \\
\hline \multirow{4}{*}{ Actividad } & \multirow{2}{*}{ Estudios } & Frecuencia & 12 & 10 & 22 \\
\hline & & $\%$ & $57,1 \%$ & $62,5 \%$ & $59,5 \%$ \\
\hline & \multirow{2}{*}{ Trabajo } & Frecuencia & 9 & 6 & 15 \\
\hline & & $\%$ & $42,9 \%$ & $37,5 \%$ & $40,5 \%$ \\
\hline \multirow{2}{*}{\multicolumn{2}{|c|}{ Total }} & Frecuencia & 21 & 16 & 37 \\
\hline & & $\%$ & $100,0 \%$ & $100,0 \%$ & $100,0 \%$ \\
\hline
\end{tabular}

Tabla 2. Edad y sexo. Fuente: Elaboración propia.

Las cuotas equilibradas son importantes para comprobar las diferenciaciones básicas en relación al resto de cuestiones planteadas. En primer lugar, el uso de internet entre los jóvenes.

\begin{tabular}{|c|c|c|c|c|c|}
\hline & & & \multicolumn{2}{|c|}{ Sexo } & \multirow[b]{2}{*}{ Total } \\
\hline & & & Hombre & Mujer & \\
\hline \multirow{6}{*}{ Uso de internet } & \multirow{2}{*}{ Uso esporádico } & Frecuencia & 0 & 1 & 1 \\
\hline & & $\%$ & $0,0 \%$ & $6,3 \%$ & $2,7 \%$ \\
\hline & \multirow{2}{*}{ Uso frecuente } & Frecuencia & 8 & 6 & 14 \\
\hline & & $\%$ & $38,1 \%$ & $37,5 \%$ & $37,8 \%$ \\
\hline & \multirow{2}{*}{$\begin{array}{l}\text { Uso muy } \\
\text { frecuente }\end{array}$} & Frecuencia & 13 & 9 & 22 \\
\hline & & $\%$ & $61,9 \%$ & $56,3 \%$ & $59,5 \%$ \\
\hline \multirow{2}{*}{\multicolumn{2}{|c|}{ Total }} & Frecuencia & 21 & 16 & 37 \\
\hline & & $\%$ & $100,0 \%$ & $100,0 \%$ & $100,0 \%$ \\
\hline
\end{tabular}

Tabla 3. Uso de internet según sexo. Fuente: Elaboración propia. 
Se puede comprobar, en la tabla 3, que el uso de internet entre los jóvenes seleccionados no se diferencia por edad ( $X 2=1,362 ; p=0,506)$, tal como se esperaba. Actualmente, el uso de internet se ha extendido entre los jóvenes de todas las edades y sexos, sin excluir prácticamente a nadie, con niveles de uso muy similares.

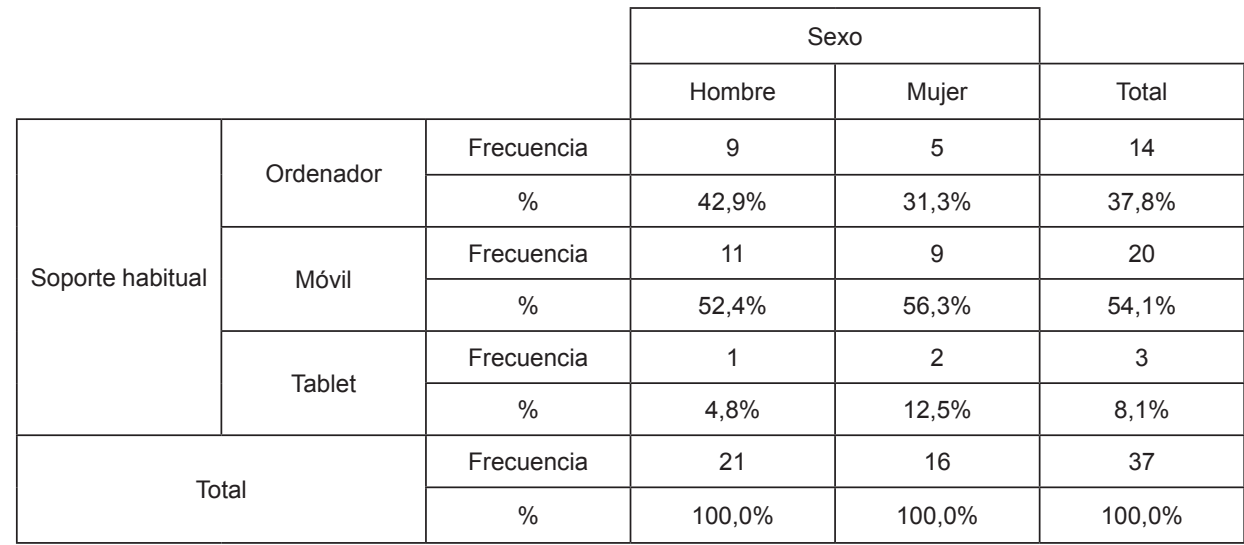

Tabla 4. Soporte habitual para el uso de internet, según sexo. Fuente: Elaboración propia.

El soporte a partir del que se establecen las conexiones ha pasado de los ordenadores a los móviles, tal como se observa en la tabla 4. En este momento, parece que las conexiones habituales se realizan con más frecuencia a partir de los móviles. Hombres y mujeres jóvenes no se diferencian en función del soporte de conexión $(X 2=1,019 ; p=0,601)$.

\begin{tabular}{|c|c|c|c|c|c|}
\hline & & & \multicolumn{2}{|c|}{ Sexo } & \multirow[b]{2}{*}{ Total } \\
\hline & & & Hombre & Mujer & \\
\hline \multirow{6}{*}{$\begin{array}{c}\text { Acceso a } \\
\text { pornografía en } \\
\text { internet }\end{array}$} & \multirow{2}{*}{ Sí } & Frecuencia & 19 & 8 & 27 \\
\hline & & $\%$ & $90,5 \%$ & $50,0 \%$ & $73,0 \%$ \\
\hline & \multirow{2}{*}{ No } & Frecuencia & 1 & 5 & 6 \\
\hline & & $\%$ & $4,8 \%$ & $31,3 \%$ & $16,2 \%$ \\
\hline & \multirow{2}{*}{ No contesta } & Frecuencia & 1 & 3 & 4 \\
\hline & & $\%$ & $4,8 \%$ & $18,8 \%$ & $10,8 \%$ \\
\hline \multirow{2}{*}{\multicolumn{2}{|c|}{ Total }} & Frecuencia & 21 & 16 & 37 \\
\hline & & $\%$ & $100,0 \%$ & $100,0 \%$ & $100,0 \%$ \\
\hline
\end{tabular}

Tabla 5. Acceso a pornografía en internet, según sexo. Fuente: Elaboración propia.

De acuerdo con la primera hipótesis, se puede comprobar en la tabla 5 como se produce una diferencia en el acceso a la nueva pornografía, a la distribuida por internet, según el sexo del joven. Se asocia el acceso a la nueva pornografía al sexo masculino de forma significativa $\left(\chi^{2}=7,611 ; p=0,022 ; C=0,413\right)$. Es cierto que el nivel de ocultación es algo mayor entre las mujeres jóvenes $(18,8 \%)$, sin embargo dicha asociación entre el acceso a pornografía y el sexo aun es dominante entre los hombres jóvenes. 


\begin{tabular}{|c|c|c|c|c|c|}
\hline & & & \multicolumn{2}{|c|}{ Sexo } & \multirow[b]{2}{*}{ Total } \\
\hline & & & Hombre & Mujer & \\
\hline \multirow{6}{*}{$\begin{array}{l}\text { Frecuencia } \\
\text { de acceso a } \\
\text { pornografía }\end{array}$} & \multirow{2}{*}{ Ocasional } & Frecuencia & 3 & 4 & 7 \\
\hline & & $\%$ & $15,8 \%$ & $50,0 \%$ & $25,9 \%$ \\
\hline & \multirow{2}{*}{$\begin{array}{l}\text { Varias veces } \\
\text { por semana }\end{array}$} & Frecuencia & 6 & 4 & 10 \\
\hline & & $\%$ & $31,6 \%$ & $50,0 \%$ & $37,0 \%$ \\
\hline & \multirow{2}{*}{ A diario } & Frecuencia & 10 & 0 & 10 \\
\hline & & $\%$ & $52,6 \%$ & $0,0 \%$ & $37,0 \%$ \\
\hline \multirow{2}{*}{\multicolumn{2}{|c|}{ Total }} & Frecuencia & 19 & 8 & 27 \\
\hline & & $\%$ & $100,0 \%$ & $100,0 \%$ & $100,0 \%$ \\
\hline
\end{tabular}

Tabla 6. Frecuencia de acceso a pornografía en internet y sexo. Fuente: Elaboración propia.

La observación anterior se completa con la frecuencia de acceso a pornografía en internet. Los grandes consumidores son todos hombres, mientras los consumidores ocasionales son más frecuentes entre las mujeres. Se puede comprobar una clara asociación, pnr lo tanto, entre el sexo masculino y el consumo frecuente de nueva pornografía $\left(\chi^{2}=7,268 ; p=0,026 ; C=0,461\right)$.

\begin{tabular}{|c|c|c|c|c|c|}
\hline & & & \multicolumn{2}{|c|}{ Edad } & \multirow[b]{2}{*}{ Total } \\
\hline & & & $16-22$ & $23-29$ & \\
\hline \multirow{6}{*}{$\begin{array}{l}\text { Frecuencia } \\
\text { de acceso a } \\
\text { pornografía }\end{array}$} & \multirow{2}{*}{ Ocasional } & Frecuencia & 1 & 6 & 7 \\
\hline & & $\%$ & $7,7 \%$ & $42,9 \%$ & $25,9 \%$ \\
\hline & \multirow{2}{*}{$\begin{array}{l}\text { Varias veces } \\
\text { por semana }\end{array}$} & Frecuencia & 7 & 3 & 10 \\
\hline & & $\%$ & $53,8 \%$ & $21,4 \%$ & $37,0 \%$ \\
\hline & \multirow{2}{*}{ A diario } & Frecuencia & 5 & 5 & 10 \\
\hline & & $\%$ & $38,5 \%$ & $35,7 \%$ & $37,0 \%$ \\
\hline \multirow{2}{*}{\multicolumn{2}{|c|}{ Total }} & Frecuencia & 13 & 14 & 27 \\
\hline & & $\%$ & $100,0 \%$ & $100,0 \%$ & $100,0 \%$ \\
\hline
\end{tabular}

Tabla 7. Frecuencia de acceso a pornografía en internet y edad. Fuente: Elaboración propia.

La diferencia por edades en el acceso a internet no es significativa $(X 2=5,141$; $p=0,076)$; en ambos grupos de edad hay prácticamente el mismo porcentaje de grandes consumidores de pornografía. Sin embargo, se puede observar una mayor presencia de consumo ocasional entre los más mayores (23 a 29 años).

Los resultados que se acaban de presentar sirven de fundamento para la segunda hipótesis, referida al mayor impacto de la nueva pornografía en los hombres, modificando sus esquemas perceptivos y, a medio plazo, los habitus de los grupos de grandes consumidores. Las entrevistas permiten apuntar algunas pistas en dicho sentido.

\section{Actitudes y esquemas de percepción}

En primer lugar, se reconocen los principales elementos propios de la modificación conductual que implica el habitus de la sexualidad formada en la era de internet y que desarrolla procesos ritualizados ${ }^{8}$; en este caso, el ambiente, las prácticas cotidianas

8 Seguimos aquí la teorización del habitus desarrollada por Bourdieu (1988, 2000). 
y los aprendizajes nuevos. Posteriormente se presentarán los cambios a nivel de los esquemas perceptivos de los sujetos, que permiten evidenciar los resultados de dicho proceso.

Para reconocer el funcionamiento del habitus, se puede partir de las modificaciones conductuales y del entorno que se hace con los jóvenes. Tal como ocurre con el espacio que brinda internet y que resulta crucial para que se desarrolle el proceso de vinculación de cada joven con su propia sexualidad. Un factor clave es el de la formación del imaginario sexual, en especial entre los jóvenes de sexo masculino, a partir de las imágenes que observan en internet (Mesch, 2009). Actualmente, ya no consultan casi a ningún adulto y tampoco tienen tanta importancia los iguales (Weber, Quiring y Daschmann, 2012). Internet aporta respuestas satisfactorias, según los jóvenes, a sus inquietudes habituales. En las entrevistas, se detallan las preguntas que les inquietan en el proceso de descubrimiento y formación de su sexualidad, desde muy jóvenes:

- ¿Cómo se inicia una relación sexual? ¿Cuáles son los preliminares aceptables y efectivos?

- ¿Cómo se puede crear un ambiente adecuado?

- ¿Cómo son los cuerpos, en detalle?

- ¿Qué prácticas son habituales? ¿Qué se puede hacer?

- ¿Qué partes del cuerpo se deben estimular y cómo se hace?

- ¿Qué accesorios puedo o debo utilizar (ropa, lubricantes, juegos, etc.)?

- ¿Cómo es la respuesta que se espera de un hombre o de una mujer (sonidos, frases, caricias, rudeza vs suavidad, intensidad aceptable, etc.)?

- ¿Cuánto dura una relación aceptable?

Las imágenes que observan en las filmaciones, les influyen de manera clara. Las relaciones sexuales consigo mismo y con otros tienen un referente formativo, así como un cierto efecto de modelado, en las filmaciones de fácil acceso ${ }^{9}$. A este respecto sí son los iguales quienes les ayudan a encontrar las páginas adecuadas, siendo los distribuidores de filmaciones similares a Youtube las más frecuentadas (http://www. tube8.com; www.hot-sex-tube.com/; http://naturalporntube.com; http://xhamster.com; etc.). Acceden directamente a partir de búsquedas sencillas y de recomendaciones directas.

Se trata de un habitus formado/modificado en privado. Como es evidente, no se trata del habitus familiar o de clase, ya que el modelo de los sujetos precedentes y de la clase social de pertenencia tiene una relevancia secundaria en relación a la sexualidad. El modificador esencial es internet y, en internet, la nueva pornografía consumida por los jóvenes. Dicho habitus implica un ejercicio de la sexualidad parcialmente diferente al de las generaciones precedentes no formadas con el apoyo de internet. La nueva pornografía forma el habitus y el habitus implica un ejercicio modificado de la sexualidad, confirmado cada día con el apoyo de otros agentes que fomentan una serie de conductas y que modifican sensiblemente el entorno de los aprendizajes.

El habitus así modificado también tiene otro efecto productivo, además de la práctica sexual, que se puede reconocer tanto en el discurso y la difusión de lo aprendido

9 La influencia de la pornografía sobre la conducta sexual ha sido estudiada en diversas ocasiones. Uno de los trabajos más relevantes puede consultarse en Ferguson y Hartley (2009). 
(es decir, la difusión y la multiplicación de sus nuevos saberes), como también en la deshistorización de los argumentos que se manejan sobre la sexualidad, que pasa a entremezclarse con su condición masculina (en el caso de los hombres). Unas prácticas sexuales, un discurso puesto en práctica, una deshistorización de la formación del género, en especial en el caso de los hombres.

Se trata de un habitus reducido por el consumo de la nueva pornografía, reducido a las experiencias observadas más que vividas, así como por el margen de conductas observadas, pero con una elaboración personal más limitada. Se produce una más amplia demanda de variantes sexuales, así como mayores detalles asociados a la conducta sexual, sin embargo, se produce una reducción de las opciones de relación interpersonal. Por ejemplo, la elección de prácticas, de conversaciones y de demandas expresadas, influidas por el consumo de nueva pornografía, se encarga a su vez de fomentar ese habitus sexual modificado que implica ritualización, simplificación. Las respuestas de los jóvenes sobre las prácticas y demandas sexuales, en el caso de los hombres, se limita a una serie de opciones muy similares en todos los casos, coincidiendo en las prácticas que se consideran deseables.

El habitus, así formado, también implica un proceso de separación de roles sexuales hombre-mujer, de acuerdo con el consumo de pornografía, con la configuración de su sexualidad y la habituación de género. La pornografía confirma los roles sexuales convencionales, dado que los papeles desarrollados por hombres y mujeres en las filmaciones sexuales son estereotipadas, pero ya no se reducen a los modelos estándar de hombre musculoso y de gran resistencia y mujer atractiva de grandes pechos. Actualmente, la pornografía muestra todo tipo de mujeres (jóvenes y mayores, delgadas y gruesas, con y sin pechos, etc.) y casi todo tipo de hombres (un requisito es la duración de las erecciones). Lo que se muestra de forma estereotipada es toda la relación sexual, de inicio a final, siendo dominantes algunos aspectos característicos de la sexualidad basada en la dominación masculina (Bourdieu, 2000):

- el deseo masculino (en las filmaciones heterosexuales) es el que debe ser satisfecho

- todo empieza y acaba con la erección masculina

- las fantasías centrales que se representan son las masculinas

Es decir, hombres y mujeres pueden ser muy diversos, pero sus relaciones sí son una representación de los modelos de género dominantes.

Para los jóvenes que se sitúan en este habitus, la relación propia de la sexualidad se prefiere con una persona con quien puedan realizar los argumentos básicos e las filmaciones, es decir, con quien acepte sus demandas y particularidades, con alguien en quien ellos se vean aceptados. Dentro de las prácticas sexuales así formadas (o deformadas), no solamente se hace presente lo conductual sino también lo actitudinal (Braun-Courville y Rojas, 2009).

Una de las actitudes que se modifica claramente, es la relativa a las prácticas de alto riesgo, es decir, aquellas que pueden tener un impacto negativo sobre la salud (Mercer y Perkins, 2014). Entre las prácticas de alto riesgo, casi todos los jóvenes han observado, con frecuencia, una gran variedad de filmaciones en las que se observan las siguientes:

- sexo vaginal sin preservativo cambiando de parejas, en grupo, etc.

- sexo anal sin preservativo con diversas parejas

- eyaculación en la boca de la pareja, tras sexo anal sin preservativo 
La familiaridad con dichas prácticas, en la nueva pornografía, es muy común, alterando la percepción sobre su aceptabilidad. El criterio dominante ya no se refiere al orden del deseo en común, sino al deseo privado que se considera aceptable.

Nuestra tercera hipótesis se centra en dichas observaciones sobre la modificación que la nueva pornografía produce sobre las prácticas sexuales de los grandes consumidores, en dos direcciones complementarias, la familiaridad con prácticas de riesgo y la demanda a sus parejas sexuales de dichas prácticas o el consumo de prostitución para realizarlas. Como se ha podido comprobar en las entrevistas, dicha hipótesis es razonable y es conveniente contrastarla con una muestra representativa.

Es necesario reconocer que la sexualidad influida por internet, por la nueva pornografía, no es un proceso atravesado por una lógica localizable desde el deseo en común o la experimentación personal, tampoco es una simple consecuencia social de un proceso corporal, sino un hecho social fortalecido por la repetición ritualizada de un habitus particular, modificado desde campos externos (en este caso, internet) que a partir de ciertos aprendizajes producen y movilizan unos efectos, como por ejemplo qué prácticas se consideran aceptables, cómo se entiende el proceso de seducción y expresión de demandas sexuales, cómo asumir el ejercicio de la sexualidad y al mismo tiempo, cómo concretarla.

\section{Ritualización progresiva de la conducta sexual}

El desarrollo de prácticas repetitivas y ritualizadas y las actitudes y los esquemas de percepción que se reconocen como efecto de la modificación ejercida por su entorno (internet y otros factores) tiene que ver con el habitus de los jóvenes en una determinada sociedad. Ritualización que tiene que ver con prácticas observadas en las filmaciones una y otra vez, así como en las opciones que ofrece internet (contactos a distancia) y en las prácticas sexuales experimentadas una y otra vez, según modelos limitados que se han ido conformando en un habitus sexual específico.

Los jóvenes, participantes en las entrevistas, no solamente se comportan como sujetos sexuales activos, sino que evidencian un disfrute significativo al fantasear con personas cercanas como si fueran sus parejas sexuales, de acuerdo con el modelo de sexualidad que ofrece la pornografía. El habitus modificado se desarrolla como un imaginario personal/colectivo de la sexualidad, pero también como un imaginario de dominación, perfectamente adaptado a la sexualidad dominante en el modelo impuesto por el patriarcado.

Las consecuencias de la ritualización son muy diversas, entre ellas se puede encontrar la incapacitación creciente para las relaciones de seducción y sexuales no pautadas (el caso extremo sería el síndrome del celibato japonés: "sekkusu shinai"), la incapacidad para mantener relaciones estables con una pareja tras algunos episodios de sexo en común, la expectativa distorsionada en las relaciones sexuales y otros efectos que actualmente seguimos estudiando en relación a los jóvenes entre 16 y 29 años.

Se produce una interiorización de las representaciones socialmente construidas de la masculinidad y la feminidad, aquellas que la nueva pornografía permite observar fácilmente de forma ritualizada. Por lo tanto, los y las jóvenes reproducen en sus autopresentaciones (Hald y Malamuth, 2008) algunos patrones referidos a las relaciones interpersonales, a las expresiones de género y a la sexualización de los cuerpos que han sido definidas por autores como Gill (2009). 
La ritualización de las relaciones se basa en la simplificación de las relaciones, desde formas rituales rígidas, dependientes de las propias rigideces que se establecen en el marco de internet y de las relaciones sexuales entre muchos jóvenes actualmente (espacios de relación, pautas de contacto consideradas aceptables, presentación en público pautada -ropa, peinados, etc.-); hasta formas rituales flexibles (con unas reglas de juego que permiten una amplia variedad de desarrollos), tal como se desarrollan todos los juegos con reglas estrictas, pero que permiten muchas modalidades de relación.

Desde la perspectiva de la sexualidad, el habitus corresponde a la formación de las opciones y prácticas sexuales del sujeto, incluyendo la disposición a usar y desarrollar valoraciones, elecciones y conductas sexuales de una determinada manera; desarrollando representaciones sociales de la sexualidad de acuerdo con ciertos modelos observados en internet e incorporándolo a través de conductas, actitudes, opiniones y producciones discursivas.

Uno de los ejemplos de dicha ritualización se observa en la formación de parejas sexuales a partir de contactos a distancia. Hay dos opciones dominantes:

a. Internet ofrece la posibilidad de seleccionar una pareja sexual, para un contacto puntual o más duradero, de forma gratuita. Las opciones de mercado son muy diversas: Badoo, Twoo, Meetic, etc. Son accesibles desde Facebook, Twitter y otras comunidades sociales, pero también con una simple búsqueda en Google. No hay mayor problema en utilizar dicha opción, pero tiene unas implicaciones claras: se elige cómo se haría en un mercado, se puede comprobar la posibilidad de tener contactos con una gran cantidad de parejas sexuales, si se produce el menor coste, en términos de responsabilidad o compromiso personal.

b. Internet también ofrece una nueva vía de acceso a la prostitución. La variedad de empresas distribuidoras de anuncios de contactos, así como de compra directa de servicios sexuales, es muy amplia. Se puede acceder a comprar servicios sexuales pagados de forma fácil, supuestamente privada y sin complicaciones (Ballester, Pozo y Orte, 2013).

Dichas modalidades de selección de parejas reducen y simplifican el proceso de elección, seducción y de paso a la acción sexual. En el caso de la prostitución, se elimina la seducción, sustituyéndola por el pago. En general, se pasa a una ritualización, según el modelo de mercado, de las relaciones sexuales interpersonales.

Tal y como se planteaba en las hipótesis, la nueva pornografía y las opciones que ofrece internet generan un efecto de ritualización de las relaciones sexuales. La nueva pornografía tendría así un gran poder de ritualización. La ritualización de las relaciones se basa en la simplificación de las relaciones, desde formas rituales rígidas (con pautas estrictas de elevada expectativa y bajo riesgo personal), hasta formas rituales flexibles (con unas reglas de juego que permiten una amplia variedad de desarrollos).

\section{Discusión y conclusiones}

No es necesario recordar que aquí se presenta una primera parte, exploratoria y cualitativa, de una investigación más ambiciosa. La contrastación rigurosa de las hipótesis requiere un tratamiento con una muestra probabilística representativa de la población. Sin embargo, la falta de fuentes de financiación de las investigaciones 
en ciencias sociales, junto al coste de un estudio como el que se necesita, limita las posibilidades de pasar a un estudio más riguroso.

Como se ha podido comprobar, parece posible mantener la primera hipótesis sin problemas. El consumo de nueva pornografía entre los hombres es superior que entre las mujeres, también consumen más tiempo que las mujeres. No se puede saber si este resultado se mantendrá en el tiempo o se equilibrará con la aparición de otras modalidades de pornografía destinadas al consumo femenino (Bakehorn, 2010). Las dimensiones del mercado de la pornografía, así como los grandes intereses comerciales que oculta, hacen pensar que dicho equilibrio seguramente es el objetivo de quienes se benefician de dicho mercado. En cualquier caso, como uno de los intereses con los que se relaciona la pornografía es el del consumo de prostitución femenina, el destinatario prioritario siguen siendo los hombres, profundizando en un modelo de sexualidad coherente con la dominación masculina característica del patriarcado.

El proceso de ritualización parece formarse en una serie de etapas que se encadenan e influyen claramente:

1. La formación del habitus sexual se ve influido por la observación frecuente, desde edades muy tempranas, de filmaciones pornográficas de fácil acceso.

2. Dicho habitus influye sobre las prácticas sexuales, en todos los momentos de las relaciones sexuales interpersonales: elección de parejas, inicio de la relación, demandas sexuales, conductas implicadas, etc.

3. La simplificación de los procesos de selección de parejas sexuales, gracias a internet, junto al habitus modificado, permiten la repetición de experiencias con diversas personas. La repetición, así como la legitimación de las relaciones sexuales interpersonales según el modelo de la nueva pornografía, producen un efecto de ritualización de las relaciones sexuales interpersonales, de la misma sexualidad en su conjunto.

La ritualización de la sexualidad (consumo de pornografía, contactos on line con nuevas parejas sexuales, experimentación de contactos pagados -prostitución-, etc.). Este tipo de prácticas que señala Bourdieu como divisiones arbitrarias que se apoyan en criterios históricos pero "naturalizados"10, como son la división socialmente construida entre los sexos y sus interpretaciones sociales de la sexualidad. Las pantallas, en términos genéricos, se convierten en un mediador fundamental en las relaciones interpersonales.

En cierta manera, se puede hablar de la sumisión de los sujetos socializados ante pantallas. De acuerdo con la tradición iniciada por Michel Foucault (1977) y sus reflexiones teóricas sobre la condición contemporánea que produce sujetos dóciles y cuerpos maleables.

Es necesario reconocer la dimensión práctica de este proceso de subordinación, reconocible a través de la transformación del sujeto sumiso (de su cuerpo, su discurso y su conducta). Tal sumisión se obtiene a través de la modificación del habitus, así como de la repetición ritualizada de prácticas, de ideas de sí y de esquemas de evaluación y percepción de la realidad (otros sujetos) que se dan por naturales (no históricos), gracias a la familiarización con las filmaciones de la nueva pornografía, y que hacen de ésta un argumento para seguir perpetuando la diferencia de género. Esta

10 Naturalización que se produce gracias a la familiaridad observada en internet. 
mirada, entonces, se puede extender no solamente al problema del sexo-género, sino también a la clase social o al deseo sexual. ${ }^{11}$

En la exploración de dichos procesos, se han planteado cuatro hipótesis que las entrevistas realizadas permiten mantener de forma consistente. En futuras investigaciones se intentará explorar de forma sistemática dichas hipótesis de investigación.

\section{Referencias bibliográficas}

Ayres, M. M. y Haddock, S. A. (2009). Therapists' approaches in working with heterosexual couples struggling with male partners' online sexual behavior. Sexual Addiction and Compulsivity, 16, 55-78. DOI: 10.1080/10720160802711952.

Ballester, L.; Pozo, R. y Orte, C. (2013). La prostitución deslocalizada. Ocultación de las nuevas modalidades de violencia. Congreso Internacional Sobre Violencia de Género: Intersecciones, Oñati, 10-12 de julio. Instituto Internacional de Sociología Jurídica.

Bakehorn, J. (2010). Women-made pornography. En: R. Weitzer (ed.), Sex for sale: Prostitution, pornography, and the sex industry (91-111). Nueva York: Routledge.

Bourdieu, P. (1988). La distinción. Madrid: Taurus.

Bourdieu, P. (2000). La dominación masculina. Barcelona: Anagrama.

Braun-Courville, D. K. y Rojas, M. (2009). Exposure to sexually explicit web sites and adolescent sexual attitudes and behaviors. Journal of Adolescent Health, 45(2), 156-162. Recuperado de http://dx.doi.org/10.1016/j.jadohealth.2008.12.004.

D'Orlando, F. (2011). The demand for pornography. Journal of Happiness Studies, 12, 51 75. DOI: 10.1007/s10902-009-9175-0.

Döring, N. M. (2009). The Internet's impact on sexuality: A critical review of 15years of research. Computers in Human Behavior, 25(5), 1.089-1.101. DOI:10.1016/j. chb.2009.04.003.

Flood, M. (2007). Exposure to pornography among youth in Australia. Journal of Sociology, 43, 45-60. DOI: 10.1177/1440783307073934.

Ferguson, C. J. y Hartley, R. D. (2009). The pleasure is momentary... the expense damnable?: The influence of pornography on rape and sexual assault. Aggression and Violent Behavior, 14(5), 323-329. DOI:10.1016/j.avb.2009.04.008.

Foucault, M. (1977). Historia de la sexualidad. Vol. Il: la voluntad de saber. México: Siglo $\mathrm{XXI}$.

Gill, R. (2009). Beyond the "Sexualization of Culture". Thesis: An Intersectional Analysis of "Sixpacks", "Midriffs" and "Hot Lesbians" in Advertising. Sexualities, 12(2), 137-160. DOI: $10.1177 / 1363460708100916$.

Hald, G. M. y Malamuth, N. M. (2008). Self-perceived effects of pornography consumption. Archives of Sexual Behavior, 37(4), 614-625. DOI:10.1080/15213269.2013.850038.

Kor, A.; Zilcha-Mano, S.; Fogel, Y. A.; Mikulincer, M.; Reid, R. C. y Potenza, M. N. (2014). Psychometric development of the Problematic Pornography Use Scale. Addictive behaviors, 39(5), 861-868. DOI: 10.1016/j.addbeh.2014.01.027. 
Mercer, D. y Perkins, L. (2013). Theorising sexual media and sexual violence in a forensic setting: Men's talk about pornography and offending. International journal of law and psychiatry, 37, 174-182. DOI: 10.1016/j.ijlp.2013.11.003.

Mesch, G. S. (2009). Social bonds and Internet pornographic exposure among adolescents. Journal of Adolescence, 32(3), 601-618. DOI: 10.1016/j.adolescence.2008.06.004.

Osborne, R. y Guasch, O. (comps.) (2003). Sociología de la sexualidad. Madrid: Centro de Investigaciones Sociológicas y Siglo XXI de España Editores.

Poza, S. A. P. y Ares, L. (2011). Sexo, poder y cine: Relaciones de poder y representaciones sexuales en los nuevos relatos pornográficos. Icono14. Revista científica de Comunicación y Tecnologías emergentes, 9(3), 98-119. DOI: http://dx.doi.org/10.7195/ ri14.v9i3.59.

Reay, B.; Attwood, N. y Gooder, C. (2013). Inventing Sex: The Short History of Sex Addiction. Sexuality \& Culture, 17(1), 1-19. DOI: 10.1007/s12119-012-9136-3.

Rogala, C. y Tydén, T. (2003). Does pornography influence young women's sexual behavior? Women's Health Issues, 13(1), 39-43. DOI: 10.1016/s1049-3867(02)00174-3.

Weber, M.; Quiring, O. y Daschmann, G. (2012). Peers, Parents and Pornography: Exploring Adolescents' Exposure to Sexually Explicit Material and Its Developmental Correlates. Sexuality \& Culture, 16(4), 408-427. DOI: 10.1007/s12119-012-9132-7.

Weitzer, R. (ed.) (2010). Sex for sale: Prostitution, pornography, and the sex industry. Nueva York: Routledge.

Young, K. S. (2008). Internet sex addiction risk factors, stages of development, and treatment. American Behavioral Scientist, 52(1), 21-37. DOI: 10.1177/0002764208321339. 